\title{
Peer review - A publisher value-add? Or essential to the scientific communication system?
}

\author{
Kent Anderson \\ Publisher, Science (AAAS), Washington
}

Critics of the journal system, for various reasons, suggest that peer review is merely one value-add in the publishing process, and that it might be provided by others or in other ways, thus not necessarily requiring a publisher. In contrast, I am going to argue that peer review in journal publishing is essential to the scientific system, and also connects it to the wider knowledge economy. Moreover, publishers currently provide the financial and intellectual independence needed for best practices in peer review. Finally, instead of treating peer review as just another value-add like copy editing or formatting, publishers must take peer review, including editorial review, more seriously again because it is what ultimately defines their role.

If publishers were not conducting peer review as part of their mission, peer review would have to be invented again. Only because publishers do it as efficiently as they do, is peer review as affordable and reliable as it is.

In what follows, first, I am going to discuss the 'Priority System' that scholarly publishing provides. Second, I show that publication is the most important prize in the Priority System. Next, I examine the essential contribution of peer review. Fourth, I consider what a peer review infrastructure must look like for best practice. In conclusion, I look at current changes to peer review and its role in the science system.

\section{The 'Priority System' as essential element of the knowledge economy}

Knowledge is non-excludable and non-rivalrous. People can not be prevented from using it.

Two people can derive the same knowledge at once. Sharing and using knowledge defines the academic system, and characterizes both research and teaching. Academics may have the idea, hypothesis, experiments, access to reagents, and so on. ${ }^{1}$

Markets, typically, are poor at providing non-excludable and non-rivalrous goods. Yet, scholarly publishing does an excellent job. Why is that?

The only way scientists can establish priority of discovery is to make their findings public. Stated differently: "The only way to make it yours is to give it away".

\footnotetext{
${ }^{1}$ This section draws inspiration from P. Stephan, How Economics Shapes Science, Harvard Univ. Press, 2012.
} 
Publishing makes knowledge rivalrous and excludable. Academics claim, "I did it first. I published it. It is mine". Priority "solves" the public good problem, providing a strong incentive for scientists to share their discoveries.

Priority encourages the production and sharing of research. It is impossible to reward people in science for effort since it's virtually impossible to monitor scientists. The priority system solves this, rewarding people for achievement rather than effort. Priority also discourages shirking - knowing that multiple discoveries of the same finding are somewhat commonplace leads scientists to exert effort - effort in generating new ideas, testing new hypothesis, make new findings. The 'Priority System' drives the advancement of science.

\section{The most important prize in the Priority System: Publication}

There are a number of prizes, but publication is the most addressable reward in the Priority System. Consider the other prizes:

- Grants: Relatively difficult to come by, and not very public.

- Tenure: Slow to come, sporadic, and difficult to achieve.

- Patents: Unusual, difficult to come by, and little academic recognition.

- Prizes: Sporadic, unpredictable, and difficult to achieve.

By contrast, publication is frequent, common, achievable, public, and informs other elements of the priority system. Publication is the most active layer, addressable by most participants in the marketplace.

\section{Peer review and priority}

Peer review refines the priority system. Editorial review is a vital part because for the review system to be excellent, the referees need to be accountable to an editor. Without it, a distributed peer review system has little accountability or reliability, and therefore far lower value.

Peer review is associated with brand value as well as reputation and prestige within the publishing environment. For scholars, publishing with certain brands advances a career significantly. It creates opportunities for tenure and promotion, with commensurate salary increases, as well further opportunities for grant monies etc.

Hence, publisher infrastructure and management of peer review is not "value add" but essential to the academic endeavor. Peer review refines the priority system across the three essential dimensions:

- Novelty: Is this information new?

- Quality: Was the research done well?

- Importance: Does this end the debate?

Peer review can help indicate whether any paper is the first, best, or last on any topic.

\section{Independence and best practice in peer review}

At the end of any research project, neither scholars nor their funders yet know how good the results are. Journals help provide that evaluation independently. Funders have financial and strategic conflicts. 
They want the research they fund to be of the highest relevance and impact so that their donors will provide them with more funds. Authors have financial and intellectual conflicts. They believe that their results are important and will enhance their reputation. Journals also have conflicts, mainly intellectual and economic. Owners and editors want to position a journal so that it remains profitable (or viable) and this may skew the acceptance of papers (e.g. papers with spectacular claims that turn out to be fraudulent). Nevertheless, the key to functioning peer review is that journals are independent, i.e. that the conflicts of the authors and funders do not impinge on the reviewing and publishing operation.

Peer review infrastructure has seven elements, all of which must be managed to the highest standard to constitute best practice. They are:

- Build a brand, e.g. reputation, market awareness, trademark.

- Recruit reviewers, e.g. editorial team, management staff, record keeping.

- Recruit papers and authors, e.g. brand power, editorial team, field expertise.

- Build and maintain systems, e.g. anti-plagiarism, internal processes, record keeping.

- Train and manage staff, e.g. job descriptions, hiring, salaries.

- Manage reviewers, grading effort, recording, more recruiting.

- Create a proper legal scenario, e.g. insurance, legal advisors, document retention policies.

All these seven infrastructure elements are essential to peer review. But it is not worth much without independence. Independence provides a check on power and bias. Traditionally, publishing has created and lived from independent revenue sources, but this is changing. As publishers become more dependent on funders and authors, e.g. by charging publication fees to authors and their funders, the question arises whether journals will remain independent or start internalizing the conflicts of authors and funders.

\section{Changes to peer review}

Media migration - from print to online to mobile - has not changed the importance of peer review. However, the shift in the business model from charging the reader to charging the authors may diminish the value of the publisher if funders start asserting that their role in the priority system is more important.

Attending to the business model brings up another issue. We know that railroad companies start failing when they don't understand that they are in the transportation business, not the railroad business. Newspapers start failing when they don't understand that they are in the news business, and not in the newspaper business.

Are publishers at risk because they think that they are in the journals business, rather than understanding that they are in the peer review business?

Changes in the peer review system must be seen as changing the existential nature of scientific publication, and not as merely tinkering around the edges of production. Post-publication peer review is essentially abdicating our role and value in the creation of a sensible scholarly record.

We need to understand that the peer review business model has significant implications:

(1) The cost of rejection is part of the value publishers deliver.

(2) As peer review becomes more complex - with new elements, more conflicts, and more authors expenses will rise.

(3) Investing in peer review is investing in a core function, not in a sideshow.

In summary, a public and viable Priority System is what makes scientists share information. A set of independent third parties is needed to let funders, governments, and researchers know how things 
worked out. Even as peer review is becoming more complex, we need to see that running high-quality, independent peer review is not a 'value-add' but a core function within the scientific and academic enterprise. 